\title{
Assessment of the Total Intra-Cranial Volume of the Igbo Population of Nigeria Using Computed Tomography
}

\author{
Sobechukwu W. I. Onwuzu, Felicitas U. Idigo, Mark C. Okeji" \\ Department of Medical Radiography \& Radiological Sciences, Faculty of Health Sciences and Technology, University of Nigeria, Enugu \\ Campus, Enugu, Nigeria
}

\author{
Email address: \\ markokeji@yahoo.com (M. C. Okeji),mark.okeji@unn.edu.ng (M. C. Okeji) \\ ${ }^{*}$ Corresponding author
}

\section{To cite this article:}

Sobechukwu W. I. Onwuzu, Felicitas U. Idigo, Mark C. Okeji. Assessment of the Total Intra-Cranial Volume of the Igbo Population of Nigeria Using Computed Tomography. Radiation Science and Technology. Vol. 3, No. 2, 2017, pp. 8-12. doi: 10.11648/j.rst.20170302.11

Received: February 11, 2017; Accepted: February 22, 2017; Published: March 24, 2017

\begin{abstract}
Total intra-cranial volume (TIV) of the Igbo population of Nigeria was carried out using stereology technique. A total of 329 adult subjects of Igbo ethnic group with no cranial and brain abnormalities aged between 18 and 87 years were enlisted into the study (males: 193 and females: 136). They were scanned with a helical dual detector (GE Hi-Speed NX/i Series 8.1). Images were obtained with a slice thickness of $3 \mathrm{~mm}$ from the base of the skull to the vertex. Employing the Cavalieri's sections method with point counting, a grid with a separation distance of $2.4 \mathrm{~cm}$ was superimposed on the sampled image sections to calculate the TIV of each subject. The mean TIV of males and females were $1298.44 \pm 90.67 \mathrm{~cm}^{3}$ and $1186.73 \pm 79.05 \mathrm{~cm}^{3}$ respectively. A comparison of the mean TIV from our study and other studies in other populations showed mild to moderate variation in values which probably due to differences geographical location and race. There was significant difference $(\mathrm{p}<0.05)$ in the value of TIV in the Igbo population when compared with some other populations such as Turkey using the same methodology. Total intra-cranial volume estimate can be applied in forensic investigations to differentiate various ethnic nationalities, in addition to clinical assessment in quantitative imaging to assess disease progression.
\end{abstract}

Keywords: Total Intracranial Volume, Computed Tomography, Stereology, Igbo Race, Nigeria

\section{Introduction}

Total intra-cranial volume (TIV) is closely related with brain volume [1] and could be used to estimate the original volume of the brain in subjects that suffer from neurological diseases associated with brain atrophy. TIV has been reported to be affected by age, gender, body mass index, geographical location, and race [2-4]. It is also invaluable for anthropological and forensic studies [5]. Several methods have been employed for obtaining the TIV but stereology with point counting has been the method of choice. It is effective and objective based on its ability to produce mathematically unbiased estimates of volumetric measurements using systematically uniform random sampling [9]. It also combines accuracy with ease of use and is highly reproducible with less coefficient of error [10]. The Igbo ethnic group has the third largest population in Nigeria and known to be migratory in nature. Total intra-cranial volume is invaluable in forensic investigations for identification. This study aimed to establish the TIV for adult Nigerian population of Igbo ethnic group and to compare same with values from other races.

\section{Materials and Methods}

The study adopted the prospective survey design and conducted at the University of Nigeria Teaching Hospital, Enugu State Nigeria. Ethical approval was obtained from the Hospital's Research Ethics Committee. Informed consent was obtained from each of the subjects. A total of 329 adult subjects of Igbo ethnic group with no cranial and brain abnormalities aged between 18 and 87 years were enlisted into the study. A dual-detector (GE Hi-Speed NX/i Series 8.1) CT machine manufactured in 2006 was used. The subject was positioned supine on the center of the couch with the upper extremities extended along the body. The head was placed on a head rest and adjusted until the median-sagittal plane 
coincided with the median centering light and the orbitomeatal base line became perpendicular to the horizontal. The head was kept stable with foam pads and Velcro straps. The scout images were planned with the inferior localizer line tilted within a range of 16 to $25^{\circ}$ and placed parallel to the skull base, at the supra-orbital ridge and cutting through the external auditory meatus. The upper localizer line was just above the vertex of the cranium. Axial images with a slice thickness of $3 \mathrm{~mm}$ were acquired and viewed with a window level of 300 and window width of 1200 . A radiologist with more than 6 years of clinical experience screened the images and those with cranial abnormalities and brain pathologies were excluded. The image sets were numbered serially, starting with the base of the skull to the vertex (Figure 1). Systematic sampling technique was then used to randomly select 8 slices from a set of each patient's images. Employing the Cavalieri's sections method with point counting, a grid with a separation distance of $2.4 \mathrm{~cm}$ was superimposed on the first of the 8 sampled image sections (Figure 2A). The position of the grid was unaltered for the rest of the images (Figure $2 \mathrm{~B}$ and $2 \mathrm{C}$ ). All intersection points that fell inside the intracranial and the cranial outline were counted. The Cavalieri's sections formula proposed by Roberts [9] was applied to calculate the TIV and Coefficient of Error (CE) for each subject based on the equation (1) below:

$$
V=T \times d^{2} \sum_{i=1}^{m} P_{i}
$$

Where:

$\mathrm{V}=$ Total Intracranial Volume

$\mathrm{T}=$ Section thickness

$\mathrm{d}=$ separation distance between test points

$\mathrm{m}=$ number of sections depicting the intracranial cavity

$\mathrm{P}_{\mathrm{i}}=$ number of points counted on a section $\mathrm{i}$

$$
\begin{aligned}
& C E=\left(\sum_{i=1}^{m} P_{i}\right)^{-1} \times\left[\frac { 1 } { 1 2 } \left(3 \sum_{i=1}^{m} P_{1}^{2}+\sum_{i=1}^{m-2} P_{i} P_{i+2}-\right.\right. \\
& \left.\left.4 \sum_{i=1}^{m-1} P_{1} P_{i+1}\right)+0.0543\left(\frac{B}{\sqrt{A}}\right)\left(m \sum_{i=1}^{m} P_{i}\right)^{1 / 2}\right]^{1 / 2}
\end{aligned}
$$

Where $\mathrm{P}=$ Number of points counted on a section $i$ $\mathrm{m}=$ number of slices systematically sampled

$\mathrm{B}=$ Total boundary length, which in this case is the length of the cranium surrounding each slice.

$\mathrm{A}=$ Total section area of each slice.

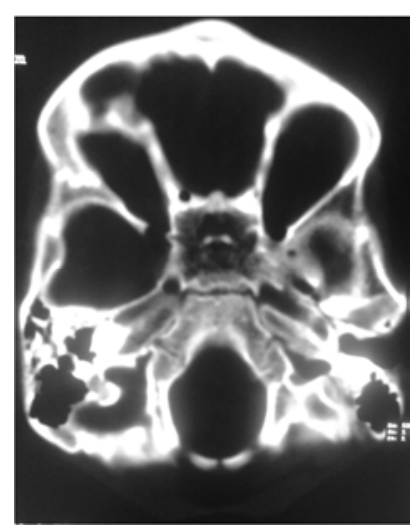

A

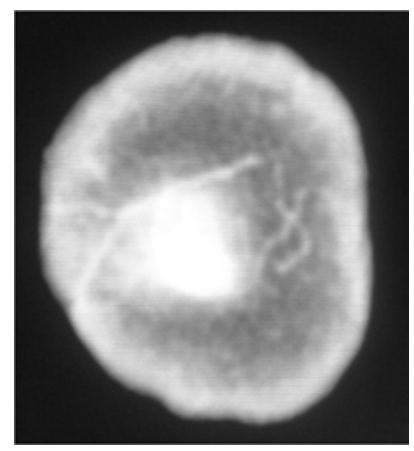

B

Figure 1. CT slice of the base of the skull (A) and the vertex of the cranium (B) which marked the inferior and superior areas covered by the localizer.

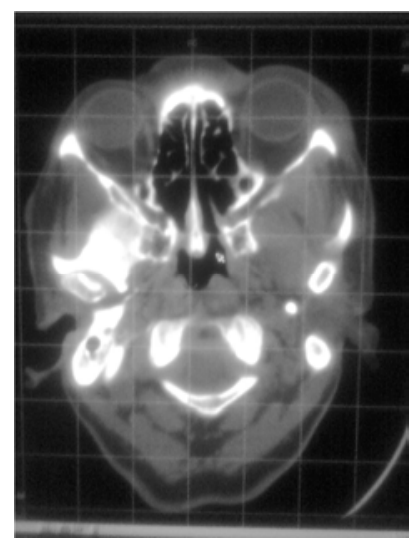

A

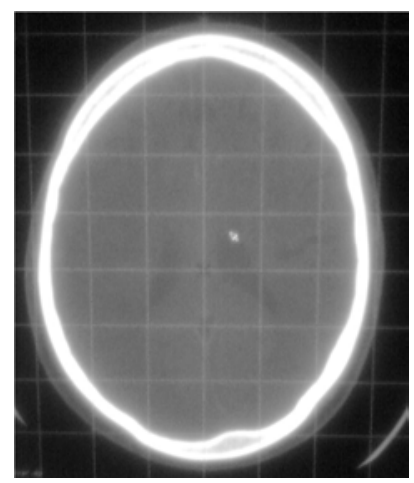

B

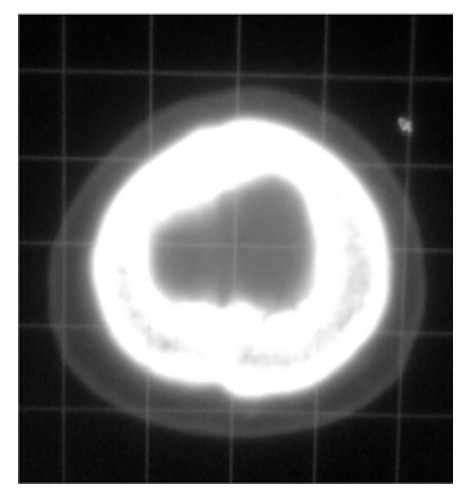

C

Figure 2. Point counting grid superimposed on the images at the skull base (A), mid portion (B) and vertex (C). 


\section{Results}

The mean TIV for the Igbo population was $1254.86 \pm$ $102.07 \mathrm{~cm}^{3}$ (males: $1298.44 \pm 90.67 \mathrm{~cm}^{3}$; females: $1186.73 \pm$ $79.05 \mathrm{~cm}^{3}$ ). Males aged48 to 57 years showed the highest values of TIV $\left(1322.23 \pm 96.77 \mathrm{~cm}^{3}\right)$ while females in the age group 18 to 27 years had the highest value $(1208.52 \pm 97.79)$. The mean Coefficient of Error (CE) was 3.52\% (males:
3.49\%; females: $3.56 \%$ ) shown in Table 1. Our stereological values and non-stereological estimates in a Nigerian and foreign populations is shown in Table 2. The mean TIV for different age groups for males and females is as shown in figure 1.

Table 1. Mean values of TIV and Coefficient of Error (\%) for males and females.

\begin{tabular}{|c|c|c|c|c|c|}
\hline Age group (yrs) & Males & & Females & & Difference \\
\hline & TIV & CE (\%) & TIV & CE (\%) & TIV \\
\hline $18-27$ & $1315.46 \pm 97.62$ & 3.46 & $1208.52 \pm 97.79$ & 3.53 & 8.85 \\
\hline $28-37$ & $1308.04 \pm 80.01$ & 3.48 & $1206.72 \pm 62.92$ & 3.42 & 8.40 \\
\hline $38-47$ & $1282.88 \pm 90.44$ & 3.66 & $1167.55 \pm 90.20$ & 3.75 & 9.88 \\
\hline $48-57$ & $1322.23 \pm 96.77$ & 3.40 & $1182.45 \pm 61.44$ & 3.58 & 11.82 \\
\hline $58-67$ & $1295.16 \pm 75.53$ & 3.34 & $1197.59 \pm 96.67$ & 3.60 & 8.15 \\
\hline $68-77$ & $1256.33 \pm 95.74$ & 3.61 & $1161.22 \pm 68.53$ & 3.56 & 8.19 \\
\hline $78-87$ & $1267.61 \pm 79.46$ & 3.55 & $1204.66 \pm 87.95$ & 3.47 & 5.23 \\
\hline Mean & $1298.44 \pm 90.67$ & 3.49 & $1186.73 \pm 79.05$ & 3.56 & 9.41 \\
\hline
\end{tabular}

*Coefficient of Error. The precision of the Total Intracranial Volume measurements using the Cavalieri sections method

Table 2. Comparison of our TIV results with other works.

\begin{tabular}{|c|c|c|c|c|c|}
\hline Population & & Technique & Males $\left(\mathrm{cm}^{3}\right)$ & Females $\left(\mathrm{cm}^{3}\right)$ & Reference \\
\hline \multirow{6}{*}{ Nigerian } & Ibo & Stereology & $1298.44 \pm 90.67$ & $1186.73 \pm 79.05$ & Present study \\
\hline & Ibo & Anthropometry & $1339.3 \pm 30.00$ & $1209.29 \pm 134.68$ & Odokuma et al [2] \\
\hline & Urhorbos & Anthropometry & $1310.65 \pm 124.57$ & $1208.77 \pm 138.65$ & \\
\hline & Edo & Anthropometry & $1353.00 \pm 103.00$ & $1253.04 \pm 139.91$ & \\
\hline & Northeast Nigeria & Anthropometry & $1424.40 \pm 137.90$ & $1331.30 \pm 201.8$ & Garba et al [11] \\
\hline & Northern Iran & Anthropometry & $1420.60 \pm 85.00$ & $1227.2 \pm 120.00$ & Golalipour et al [14] \\
\hline \multirow{5}{*}{ Non-Nigerian } & India & Anthropometry & $1152.81 \pm 279.16$ & $1117.82 \pm 99.09$ & Manjunath et al [12] \\
\hline & Korea & Anthropometry & $1470.00 \pm 107.00$ & $1317.00 \pm 117.00$ & Hwang et al [13] \\
\hline & Turkey & Water filling & $1389.50 \pm 96.50$ & $1134.5 \pm 94.30$ & Sahin et al [14] \\
\hline & Greece & Stereology & $1323.0 \pm 180.7$ & & Mazonakis et al [15] \\
\hline & Turkey & Stereology & $1474.67 \pm 93.00$ & $1252.32 \pm 72.00$ & Acer et al [16] \\
\hline
\end{tabular}

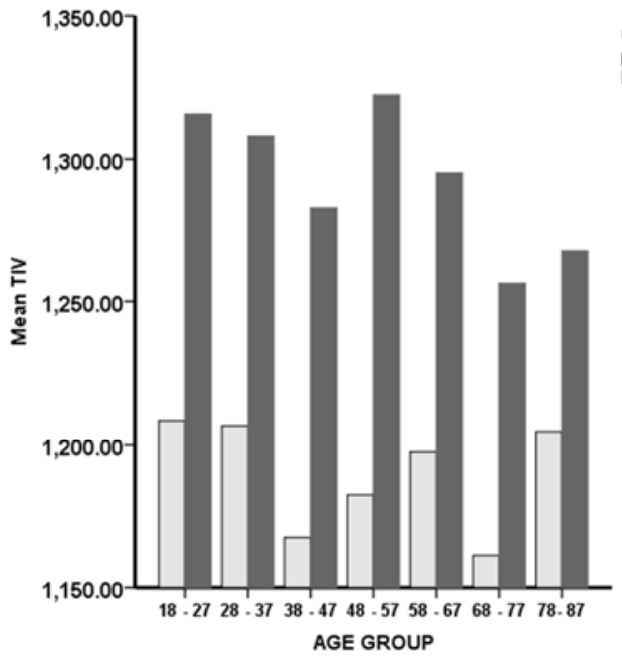

Figure 3. Bar chart of mean TIV for males and females.

\section{Discussion}

Our study revealed a mean TIV of $1252.26 \pm 102.08 \mathrm{~cm}^{3}$ $\left(1298.44 \pm 90.67 \mathrm{~cm}^{3}\right.$ for males and $1186 \pm 79.05 \mathrm{~cm}^{3}$ for females) among the Igbo population. The Igbo men have higher TIVs than the women. Males TIVs peaked in the age range age 48 to 57 years while that of females peaked at 18 to 27 years. This finding is contrary to the assertion of some authors [7, 17] who believed that TIV reaches its peak and does not change its size subsequently. The female population of the Igbo population showed close similarity to the assertion.

Our study showed that on the average, Igbo men had a TIV $9.4 \%$ greater than their females. This is similar to a study by Sadakat [18] in which he found cranial capacity of the female to be $1 / 10^{\text {th }}$ of the males. This however varied with a study of the Indian population which recorded a $12 \%$ difference [1].

Our values were similar to a work on Caucasian population [15] which reported a mean TIV of $1323.0 \pm$ $180.7 \mathrm{~cm}^{3}$. An earlier study had reported Caucasians to have higher mean TIV values than the Negroes [19]. A comparison of the mean TIV from our study and other studies in other populations showed mild to moderate variation in values which probably due to differences geographical location and race as reported in literature [3, 4]. The differences in our values from that of Odokuma et al [2] from the same Igbo population may be due to the methodology (anthropometry) which may have overestimated the TIV as affirmed by other authors [3, 14, 20]. Anthropometry overestimates the TIV due to contributions from the subject's hair, scalp and cranium. There was significant difference $(p<0.05)$ in the 
value of TIV in the Igbo population when compared with some other populations such as Turkey using the same methodology [16].

The TIV measurement is invaluable for clinical assessment especially in quantitative imaging in radiology [9]. Normalized values can be employed to correct for variations in intracranial structures as well as changes resulting from pathological processes $[1,21]$. Volumetric measurements of rates of atrophy have been suggested as markers of disease progression in therapeutic trials for ailments such as Alzheimer's disease and other neurodegenerative diseases [22-24]. This will require serial acquisition of images to monitor brain volume changes. The serial image acquisition should be carried out by experts in order to avoid subtle differences occasioned by small variations in patient positioning and voxel changes [1,25].

The TIV remains fairly stable and is unaltered by disease processes; hence it can comfortably be used as a control for variations in longitudinal measurements of brain volume changes. It remains the best estimate for the pre-morbid brain size as the TIV/brain ratio has been shown to be within $1 \%$ of each other $[1,26]$.

A major strength of this study is that it provided an unbiased estimate of the TIV of the Igbo population using stereology which to the best of the researcher's knowledge had not been conducted. A limitation of this study however, is that it did not assess the effect of inter-observer variation on the accuracy of TIV measurements. This study therefore forms a foundation for further studies in TIV in Igbo population.

\section{Conclusion}

The total intra-cranial volume of adult subjects of Igbo population was determined using stereology technique. There was mild to moderate variation in TIV values among different races. We therefore suggest the use of total intracranial volume estimate in forensic investigations to differentiate various ethnic nationalities, in addition to clinical assessment in quantitative imaging to assess disease progression.

\section{Abbreviations}

i. TVS: Total intra-cranial volume

ii. GE: General Electric

\section{Declaration}

Ethical approval: Ethical approval was obtained from the Research and Ethics Committee of University of Nigeria Teaching Hospital, Enugu.

Informed consent was obtained from each of the participants.

\section{Consent to Publish}

Not applicable

\section{Authors' Contributions}

SWIO and FUI participated in data collection while SWIO and MCO did data analysis and discussion.

\section{Acknowledgement}

The authors appreciate the co-operation obtained from the hospital and clinics during the course of the research.

\section{Availability of Data and Materials}

Data and materials are available.

\section{References}

[1] Whitwell JL, Crum WR, Watt HC, Fox NC. Normalization of Cerebral Volumes by Use of Intracranial Volume: Implications for Longitudinal Quantitative MR Imaging. AJNR Am J Neuroradiol 2001; 22 (8): 1483-9.

[2] Odokuma EI, Akpuaka FC, Igbigbi PS, Otuaga PO, Ejebe D. Patterns of cephalic indexes in three West African populations. African Journal of Biotechnology 2012; 9 (11): 1658-62.

[3] Haack DC, Meihoff EC. A method for estimation of cranial capacity from cephalometric roentgenograms. Am J Phys Anthropol 1971; 34 (3): 447-52.

[4] Golalipour M, Jahanshahi M, Haidari K. Estimation of Cranial Capacity in 17-20 Years Old in South East of Caspian Sea Border (North of Iran). Int J Morphol 2005; 23 (4): 301-4.

[5] Tan Q-F, Yu Q, Gao S, Huang F-J. Comparative study for the methods on measuring intracranial hemorrhage volume. Fa Yi Xue Za Zhi 2006; 22 (5): 335-7.

[6] Sgouros S. Skull vault growth in craniosynostosis. Child's Nervous System 2005; 21 (10): 861-70.

[7] Lyden PD, Zweifler R, Mahdavi Z, Lonzo L. A rapid, reliable, and valid method for measuring infarct and brain compartment volumes from computed tomographic scans. Stroke 1994; 25 (12): 2421-8.

[8] Jack CR, Petersen RC, O’Brien PC, Tangalos EG. MR-based hippocampal volumetry in the diagnosis of Alzheimer's disease. Neurol 1992; 42 (1): 183-183.

[9] Roberts N, Puddephat MJ, McNulty V. The benefit of stereology for quantitative radiology. Br J Radiol 2000; 73 (871): 679-97.

[10] West MJ. Introduction to Stereology. Cold Spring Harb Protoc 2012; 2012 (8):pdb.top070623.

[11] Garba AU, Shapu SH, Garba MA, Muhammad AM, Maina $\mathrm{MB}$, Yaro AU, et al. Assessments of Cranial Capacities in a North-Eastern Adult Nigerian Population. Journal of Applied Sciences 2011; 11: 2662-5.

[12] Manjunath KY. Estimation of Cranial Volume - An Overview of Methodologies. Journal of Anatomical Society of India 2002; 51 (1): 85-9.

[13] Hwang YI, Lee KH, Choi BY, Lee KS, Lee HY, Sir WS, et al. Study on the Korean adult cranial capacity. J Korean Med Sci 1995; 10 (4): 239-42. 
[14] Sahin, Acer N, Sonmez OF, Emirzeoglu M, Basaloglu H, Uzun A, et al. Comparison of four methods for the estimation of intracranial volume: a gold standard study. Clinical Anatomy 2007; 20 (7): 766-73.

[15] Mazonakis M, Karampekios S, Damilakis J, Voloudaki A, Gourtsoyiannis N. Stereological estimation of total intracranial volume on CT images. Eur Radiol 2004; 14 (7): 1285-90.

[16] Acer N, Sahin B, Bas O, Ertekin T, Usanmaz M. Comparison of three methods for the estimation of total intracranial volume: stereologic, planimetric, and anthropometric approaches. 2007; 58 (1): 48.

[17] Moore KL, Dalley AF. Clinically Oriented Anatomy. 5th Edition. Lippincott Williams \& Wilkins; 2006.

[18] Sadakat A, Sinha AP, Jethani SL, Rohatgi RK, Anamika K. Study of Cranial Capacity of Adult North Indian Human Skulls \& its Sexual Dimorphism. International Journal of Scientific Study 2014; 1 (5): 29-31.

[19] Rushton JP, Osborne RT. Genetic and environmental contributions to cranial capacity in Black and White adolescents. Intelligence 1995; 20 (1): 1-13.

[20] Ertekin T, Acer N, Turgut AT, Aycan K, Özçelik Ö, Turgut M. Comparison of three methods for the estimation of the pituitary gland volume using magnetic resonance imaging: a stereological study. Pituitary 2011; 14 (1): 31-8.

[21] Free SL, Bergin PS, Fish DR, Cook MJ, Shorvon SD, Stevens JM. Methods for normalization of hippocampal volumes measured with MR. AJNR Am J Neuroradiol 1995; 16: 63764.

[22] Fox NC, Freeborough PA, Rossor MN. Visualisation and quantification of rates of atrophy in Alzheimer's disease. Lancet 1996; 348: 94-7.

[23] Simon JH, Jacobs LD, Campion MK. A longitudinal study of brain atrophy in relapsing multiple sclerosis. Neurol 1999; 53: $139-48$.

[24] Ge Y, Grossman RI, Udupa JK. Brain atrophy in relapsingremitting multiple sclerosis and secondary progressive multiple sclerosis: longitudinal quantitative analysis. Radiology 2000; 214: 665-70.

[25] Freeborough PA, Woods RP, Fox NC. Accurate registration ofserial 3D MR brain images and its application to visualizingchange in neurodegenerative disorders. J Comput Assist Tomogr 1996; 1996: 1012-22.

[26] Blatter DD, Bigler ED, Gale SD. Quantitative volumetric analysis of brain MR: normative database spanning 5 decades of life. Neuroradiol 1995; 16: 241-5. 